\title{
Osteoarthritis: New Perspectives
}

\section{Odile Gabay*}

Cartilage Biology and Orthopedics Branch, Cartilage Molecular Genetics Group, National Institute ofArthritis, Musculoskeletal and Skin Disease, NIAMS, NIH, BIdg 50, Bethesda, MD 20892, USA

Osteoarthritis $(\mathrm{OA})$ is the most common and frequent disease in rheumatology. Aging and obesity are the two main risk factors linked to $\mathrm{OA}$, and because of the aging population and the increasing rates of obesity, the number of OA patients stands to increase dramatically. To date, 46 million adults in the United States-more than 50 percent of adults aged 50 and over-have been diagnosed with OA: it is predicted that by the year 2030, that figure will rise to around 70 million [1].

In the last two decades, many mechanisms have been discovered about this disease. Cartilage, which previously was considered inactive tissue, is now actively studied as the main active tissue of joints; it is being studied as part of the whole joint, including other tissues as subchondral bone, synovium and tendons. OA mainly targets the major joints (knee, hip, and back) but commonly affects the hands, elbows, and ankles. Osteoarthritis is a degenerative disease caused by the loss of cartilage and inflammation: it is often-but not alwaysaccompanied by pain and sometimes occurs subsequent to an injury as primary or secondary $\mathrm{OA}$. The disease results in an imbalance between catabolic and anabolic factors in cartilage. Chondrocytes, osteoblasts, and synoviocytes seem to cross-talk and be part of the process. Current molecular and genetic approaches have led to the identification of more complex mechanisms.

The practical questions this paper addresses are: how should we treat $\mathrm{OA}$ in the next 10 years, and how can we help aging patients manage their arthritis?

Although the ultimate goal for the treatment of OA would be to halt the disease progression and restore cartilage damage and relieve pain, effective cures are not currently available and recommendations for treatment vary. The European League Against Rheumatism (EULAR), the OsteoArthritis Research Society International (OARSI) and the American College of Rheumatology (ACR) have developed various recommendations for treating $\mathrm{OA}$, depending on its location [2-8].

Roddy and Doherty have written a critical review of EULAR's and ACR's recommendations for treating OA, which are generally similar, combining non pharmacological and pharmacological approaches [9]. Rannou et Poiraudeau recently published an exhaustive list of nonpharmacological treatments for OA, echoing the work done by Felson et al. [10] on malalignment: treatment regimens range from orthosis to exercise, patient education, and diet, depending on $\mathrm{OA}$ location [10-13]. The recent study by Richette et al. [14] concerning obesity and diet and OA highlighted the importance of such non pharmacological treatments [14]. Briefly, non pharmacologic treatment include orthosis (such as using insoles and specific shoes, depending on the location), moderate excercise (specific postural exercises, swimming, walking), acupuncture, thermotherapy, and walking aids such as canes crutches, frames, wheeled walkers, and walking sticks. Diet and weight loss are also recommended, although these are a challenge and a difficult process for obese patients. Defining a weight objective could lead to improvement not only with OA but also with metabolic and cardiovascular diseases. No matter the recommended treatment, education and information are vital for effecting patient compliance. Physicians and therapists play an important role in providing such education during time spent with their patients: regular phone calls may help as well.

The pharmacological approach for the treatment of OA differs from Europe to the U.S., although both approaches share the common goal of managing pain while also managing disability. Pharmacological guidelines for the management of OA recommend acetaminophen up to $4 \mathrm{~g} /$ day as first-line therapy. Alternative pharmacological therapy should be used only in the presence of an inadequate response and severe pain. If acetaminophen cannot control symptoms or if inflammation signs are detected, the use of NSAIDs at the lowest dose is recommended, with consideration of a gastro-protective agent. OARSI and EULAR guidelines recommend that if patients don't respond to oral analgesics, they should receive intra-articular injections of either corticosteroids or hyaluronate followed by the use of opioids and narcotics only when all other pharmacological options have been considered. Surgery, including joint replacement, is recommended only as the last option [15]. Finally, the use of topical NSAIDs, capsaicin, and SYSADOA (SYmptomatic Slow-Acting Drugs for OA, which includes avocado/soybean unsaponifiables (ASU), chondroitin, diacerein, and glucosamine) is recommended by EULAR and OARSI.

\section{Which Treatment for the Future?}

The search for new treatments and possible molecules targets has raised a number of important questions: Does the disease start in the cartilage or in the subchondral bone? [16] What comes first, altered mechanical loading, bone sclerosis, or cartilage degradation? [17-19] Recent discoveries have shown that subchondral bone is involved in OA pathophysiology, [20] which raises further questions: If subchondral bone initiates OA, what initiates bone imbalance? This question finds its analog in other diseases: What initiates cancer? Further questions logically follow: is OA a single disease? The comparison of OA of the hands, spine, hip, and knee shows a multiple factorial disease. When we look closer again, we can spot an intricacy of the different tissues. Subchondral bone contains a rich and huge vasculature. Moreover, hip and knee OA are largely studied, but what about hand OA? The problem of obesity and metabolic syndrome has led to a reconsideration of the factors involved in hand OA [21]. Differences in gender, genetic factors, age, and previous injury have been shown to play a role as well. Will only one Disease Modifying OsteoArthritis Drug (DMOAD) work? Is there a single "magic bullet" therapy, or is a combination therapy more effective? Dexamethasone, a glucocorticoid treatment that abolishes pro-inflammatory cytokines and injury defects, is one example of a therapy with a double target [22]. While imagining new identified targets with specific inhibitors, as signaling pathways, MMPs, chromatin modifying enzymes, we could ask: Could we cumulate all the new inhibitors? The molecular network in $\mathrm{OA}$ is well interconnected and the balance between the different

Corresponding author: Odile Gabay, Cartilage Biology and Orthopedics Branch, Cartilage Molecular Genetics Group, National Institute of Arthritis, Musculoskeletal and Skin Disease, NIAMS, NIH, Bldg 50, Bethesda, MD 20892, USA, E-mail: gabayo@mail.nih.gov

Received October 12, 2011; Accepted November 04, 2011; Published November 07, 2011

Citation: Gabay O (2012) Osteoarthritis: New Perspectives. J Spine 1:e101. doi:10.4172/2165-7939.1000e101

Copyright: ( 2012 Gabay O. This is an open-access article distributed under the terms of the Creative Commons Attribution License, which permits unrestricted use, distribution, and reproduction in any medium, provided the original author and source are credited. 
mechanisms is fragile. Disturbing a mechanism in trying to balance a pathologic pathway could lead to imbalance in another pathwaywhich is precisely what happened with MMP inhibitors years ago [23].

A brief review of the current new molecules in clinical development shows two main targets: pain and structural modification [24]. Targeting pain, we can cite 5 anti-NGF (Nerve Growth Factor) humanized antibodies (i.e., Tanezumab), a 5-LOX (lipooxygenase) inhibitor, a PG (Prostaglandines) inhibitor, NSAID, a Hyaluronic Acid (HA), and an HA combined with steroids. Targeting the structural modification, we can cite a pro-anabolic growth factor (BMP-7), a salmon calcitonin for bone and articular surface preservation, a MAP (Mitogen Activated Protein) kinase inhibitor, an iNOS (Nitric Oxide Synthase) inhibitor, a pro-anabolic growth factor, FGF-18, an antiIL1 antibody, Canakinumab, a pro-anabolic and anti-inflammatory autologous bone marrow stem cells process, and an IKK (Inhibitor of Kappa Kinase) inhibitor. The modality of drug delivery also needs to be considered: locally versus systemic (IA, IV, oral, topic) [24] OA has multiple etiologies and interconnecting pathways, so targeting only one molecule does not seem the solution to effectively treating OA: the single compound for treating OA will most probably never exist.

In conclusion, all these questions-about the initiator of the disease, the different targets, the differences between OA locations, and aging and obesity mechanisms-have not yet found definitive answers and remain to be elucidated before planning new therapeutical designs for treatment of OA in the future. Discovering the precise role of subchondral bone or cartilage and identifying a precise order of events happening in the pathology remain the first challenges of the future decade. Meanwhile, much can be done already to treat this multifactorial disease with a variety of simultaneous treatments and common sense-particularly dealing with obesity, which has become the challenge of the future decade.

\section{Acknowledgements}

This work has been supported by the Intramural Research Program of the National Institute of Arthritis and Musculoskeletal and Skin Diseases of the National Institutes of Health.

\section{References}

1. Aletaha D, Smolen JS (2006) The American College of Rheumatology N (ACR-N) debate: going back into the middle of the tunnel ? Comment on the articles by Siegel and Zhen and by Boers. Arthritis Rheum 54: 377-378.

2. Pendleton A, Arden N, Dougados M, Doherty M, Bannwarth B, et al. (2000) EULAR recommendations for the management of knee osteoarthritis: report of a task force of the Standing Committee for International Clinical Studies Including Therapeutic Trials (ESCISIT). Ann Rheum Dis 59: 936-944.

3. Mazieres B, Bannwarth B, Dougados M, Lequesne M (2001) EULAR recommendations for the management of knee osteoarthritis: Report of a task force of the Standing Committee for International Clinical Studies Including Therapeutic Trials. Joint Bone Spine 68: 231-240.

4. Jordan KM, Arden NK, Doherty M, Bannwarth B, Bijlsma JW, et al. (2003) EULAR Recommendations 2003: an evidence based approach to the management of knee osteoarthritis: Report of a Task Force of the Standing Committee for International Clinical Studies Including Therapeutic Trials (ESCISIT). Ann Rheum Dis 62: 1145-1155.

5. Zhang W, Doherty M, Arden N, Bannwarth B, Bijlsma J, et al. (2005) EULAR evidence based recommendations for the management of hip osteoarthritis: report of a task force of the EULAR Standing Committee for International Clinical Studies Including Therapeutics (ESCISIT). Ann Rheum Dis 64: 669681.

6. Zhang W, Doherty M, Leeb BF, Alekseeva L, Arden NK, et al (2007) EULAR evidence based recommendations for the management of hand osteoarthritis: report of a Task Force of the EULAR Standing Committee for International Clinical Studies Including Therapeutics (ESCISIT). Ann Rheum Dis 66: $377-$ 388 .
7. Zhang W, Moskowitz RW, Nuki G, Abramson S, Altman RD, et al. (2007) OARSI recommendations for the management of hip and knee osteoarthritis, part I: critical appraisal of existing treatment guidelines and systematic review of current research evidence. Osteoarthritis Cartilage 15: 981-1000.

8. Zhang W, Moskowitz RW, Nuki G, Abramson S, Altman RD, et al. (2008) OARSI recommendations for the management of hip and knee osteoarthritis, Part II: OARSI evidence-based, expert consensus guidelines. Osteoarthritis Cartilage 16: 137-162.

9. Roddy E, Doherty M (2003) Guidelines for management of osteoarthritis published by the American College of Rheumatology and the European League against Rheumatism: why are they so different? Rheum Dis Clin North Am 29: 717-731.

10. Rannou F, Poiraudeau S (2010) Non-pharmacological approaches for the treatment of osteoarthritis. Best Pract Res Clin Rheumatol 24: 93-106.

11. Hunter DJ, Zhang Y, Niu J, Tu X, Amin S, et al. (2005) Structural factors associated with malalignment in knee osteoarthritis: the Boston osteoarthritis knee study. J Rheumatol 32: 2192-2199.

12. Felson DT, Goggins J, Niu J, Zhang Y, Hunter DJ (2004) The effect of body weight on progression of knee osteoarthritis is dependent on alignment. Arthritis Rheum 50: 3904-3909.

13. Felson DT (2004) Risk factors for osteoarthritis: understanding joint vulnerability Clin Orthop Relat Res 427: S16-S21.

14. Richette P, Poitou C, Garnero P, Vicaut E, Bouillot JL, et al. (2010) Benefits of massive weight loss on symptoms, systemic inflammation and cartilage turnover in obese patients with knee osteoarthritis. Ann Rheum Dis 70: 139144.

15. Berenbaum F (2008) New horizons and perspectives in the treatment of osteoarthritis. Arthritis Res Ther 10 Suppl 2: S1.

16. Goldring SR, Goldring MB (2010) Bone and cartilage in osteoarthritis: is what's best for one good or bad for the other? Arthritis Res Ther 12: 143.

17. Buckwalter JA, Mankin HJ, Grodzinsky AJ (2005) Articular cartilage and osteoarthritis. Instr Course Lect 54: 465-480.

18. Kurz B, Lemke AK, Fay J, Pufe T, Grodzinsky AJ, et al. (2005) Pathomechanisms of cartilage destruction by mechanical injury. Ann Anat 187: 473-485.

19. Lee JH, Kisiday J, Grodzinsky AJ (2003) Tissue-engineered versus native cartilage: linkage between cellular mechano-transduction and biomechanical properties. Novartis Found Symp 249: 52-64.

20. Mastbergen SC, Lafeber FP (2011) Changes in subchondral bone early in the development of osteoarthritis. Arthritis Rheum 63: 2561-2563.

21. Gabay O, Hall DJ, Berenbaum F, Henrotin Y, Sanchez C (2008) Osteoarthritis and obesity: experimental models. Joint Bone Spine 75: 675-679.

22. Lu YC, Evans CH, Grodzinsky AJ (2011) Effects of short-term glucocorticoid treatment on changes in cartilage matrix degradation and chondrocyte gene expression induced by mechanical injury and inflammatory cytokines. Arthritis Res Ther 13: R142.

23. Milner JM, Cawston TE (2005) Matrix metalloproteinase knockout studies and the potential use of matrix metalloproteinase inhibitors in the rheumatic diseases. Curr Drug Targets Inflamm Allergy 4: 363-375.

24. Matthews GL, Hunter DJ (2011) Emerging drugs for osteoarthritis. Expert Opin Emerg Drugs 16: 479-491. 